\title{
Analysis and Suppressing Speed Fluctuations in Brushless DC Motors
}

\author{
M. Reşit ÇORAPSIZ, H. KAHVECİ and M. Fatih ÇORAPSIZ
}

\begin{abstract}
The fluctuations in both speed and torque magnitudes during operation are among the major disadvantages of brushless DC motors. These fluctuations occur due to both the commutation of the inverter switches and the phase winding inductances. This case can lead to major problems, especially in applications which are required constant speed and constant torque. In this work, it was aimed to reduce speed fluctuations that occur in brushless DC motors. Firstly, the simulation model was created by using the dynamic equations of the brushless DC motor. Secondly, a region selective circuit was designed for use in commutation regions. Finally, the commutation signals were generated from the magnitude of the torque produced by the motor. Consequently, the proposed technique was controlled under different speed conditions and was shown that the speed fluctuations can be reduced without the difficult calculations of the commutation time. According to the results obtained, it was observed that the speed fluctuations were significantly reduced.
\end{abstract}

Index Terms-BLDC Motor (BLDCM), Commutation, Reduction of Speed Fluctuation, DC Link Voltage Control, MATLAB/Simulink.

\section{INTRODUCTION}

I N RECENT YEARS, Brushless DC motor has started to be used frequently in many motion source applications. These motors are use to convert electrical energy into mechanical energy or to transfer energy as in other electric motors. These motors have a wide range of applications such as electric

MUHAMMED REŞiT ÇORAPSIZ, is with Department of Electric and Energy, Bayburt University, Bayburt, Turkey, (e-mail: rcorapsiz@bayburt.edu.tr).

(iD https://orcid.org/0000-0001-5477-5299

MUHAMMED FATIH ÇORAPSIZ, is with Department of ElectricalElectronics Engineering of Atatürk University, Erzurum, Turkey, (e-mail: corapsiz@atauni.edu.tr).

(iD https://orcid.org/0000-0001-5692-8367

HAKAN KAHVECI, is with Department of Electrical-Electronics Engineering of Karadeniz Technical University, Trabzon, Turkey, (e-mail: hknkahveci@ktu.edu.tr).

(iD https://orcid.org/0000-0001-9369-2330

Manuscript received May 24, 2019; accepted July 9, 2019.

DOI: $10.17694 /$ bajece. 569774 vehicles, aerospace, space technologies and medical fields and have a number of advantages compared to DC and AC motors. The main advantages of using BLDC motors are high power efficiency, less noise, higher torque according to the weight/inertia ratio and higher speed. Besides these motors can be both manufactured in various sizes and easy controlled [1]. In addition, since BLDC motors do not have brushes and collectors that require extra equipment and increase friction factor, they need less maintenance, no arc is generated during operation, and have a longer life compared to DC motors. In spite of these advantages, the use of sensors in various structures to determine the rotor position in order for the BLDC motor to require an inverter and to control this inverter constitutes a disadvantage in terms of cost [2]. With the development of power electronic components, BLDCM has shown a very rapidly development. The major disadvantage of these motors is the fluctuations in torque, current and velocity in commutation intervals. The commutation operation on the BLDC motor is carried out electronically via an inverter. Since the currents of the phase windings change during the commutation process, the fluctuations in the phase currents are also seen in the torque and velocity magnitudes. These fluctuations are caused by the fact that the switches in the inverter are electrically change position in the direction of the information they receive from a hall effect sensor at every 60 degrees.

There are studies in the literature on the reduction of torque ripples rather than speed fluctuations. For example, a new DC link voltage control strategy was proposed with the SEPIC converter to equalize the slopes of the incoming and outgoing phase currents during the commutation and adjust the desired DC link voltage in order to reduce the torque fluctuations at both low and high speeds [3]. In [4], the modified SEPIC converter and diode clamped multilevel inverter (DCMLI) were used for the torque ripple reduction. With this study, both noise problems were reduced and higher yield was obtained from brushless DC motor. In [5], two different current control methods were used to reduce the torque ripples caused by the phase commutation. These methods; control of source current and control of the phase currents of the motor. These two control methods were compared and it was observed that the control of the phase currents is more effective. In order to keep constant of the non-conducting phase current, a region selective circuit was designed with a new switching technique and applied to the BLDCM at the commutation time, both the commutation times were analyzed and the CUK converter was used to obtain the desired voltage value at the time of commutation [6]. In [7], in order to reduce 
the torque ripples in the commutation times, it was carried out by using a single current sensor, it was aimed to balance the current slopes of the incoming and outgoing phase currents with a suitable switching method. With this method, decreases and increases in the phase currents and output torque have been eliminated. In [8], a new PWM technique has been performed to keep both the non-commutation phase current constant and shorter the commutation time. This technique was applied to the non-commutation phase at commutation times and has been yielded very efficient results. In [9], a new current control method has been proposed in order to reduce the ripples in the conducting and commutation regions for Brushless DC motor with non-ideal back electromotive force (EMF). With this method, they were use both the calculation of the commutation times and the pulse width modulation (PWM) to disable the free-wheeling diode (FWD) in the inactive phase. In [10], has been designed a detailed current stabilization method and a commutation timer, both theoretical and experimental, which are highly effective in reducing both the commutation torque ripples and the determination of the commutation endpoint. In [11], has been proposed to reduce the torque ripples in brushless DC motor from the nominal speed to the moment of stopping and the effectiveness of the presented technique was analyzed in detail with theoretical and experimental results.

In this study, it was aimed to decrease the speed fluctuations occurring during the operation at the commutation intervals of the BLDC motor. Two different DC link voltages were used to perform this operation. The first one is for conduction regions and the second for commutation regions. In order to determine the commutation intervals, the relationship between the torque constant of the motor and the desired torque magnitude was calculated. When the results obtained were compared with the conventional BLDC speed control, it was observed that the fluctuations in the rotor speed were significantly suppressed.

\section{ANALYSIS OF SPEED FLUCTUATION IN BRUSHLESS DC MOTOR}

The equivalent circuit for the BLDCM drive system with three-phase symmetrical stator winding is shown in Fig.1.

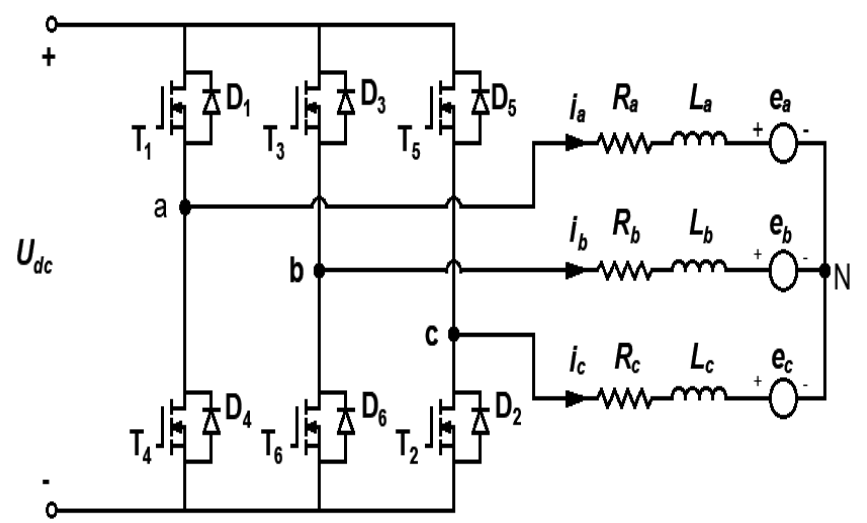

Fig. 1 Equivalent circuit for BLDC motor drive

As can be seen from Fig.1, a three-phase, two-level inverter was used for BLDCM in this study. All of the switches in the inverter was designed with power MOSFETs. Since
MOSFETs do not have the ability to block the voltage in the opposite direction, the anti-parallel free-wheeling diodes were connected to the switches. These diodes were used to reset the current which induced in the windings of the phase outgoing from the conduction. In this case, are occurs ripples on the speed, current and torque magnitude of the BLDC motor. In addition, in BLDC motors, the current of each phase is carried out in a finite current transfer process depending on the rotor speed. During this process, when the current ends in one phase and starts in the other phase, the ripples occurs due to the phase winding inductances. These ripples are mainly caused by the switching of the inverter, the non-ideal trapezoidal back EMFs and the commutations of the currents that are incoming and outgoing pahse. The ripples occuring due to the switching can be accomplished by adjusting the rotor inertia during the mechanical design of the brushless DC motor. But the commutation torque ripples, affects the motor performance at greater intensity and amplitude [12].

When the Kirchhoff Voltage Law is applied to each phase separately in the BLDCM equivalent circuit in Fig.1, the three phase terminal voltages can be expressed as follows;

$$
\begin{aligned}
& u_{a}=R_{a} i_{a}+L_{a} \frac{d i_{a}}{d t}+e_{a}+u_{N} \\
& u_{b}=R_{b} i_{b}+L_{b} \frac{d i_{b}}{d t}+e_{b}+u_{N} \\
& u_{c}=R_{c} i_{c}+L_{c} \frac{d i_{c}}{d t}+e_{c}+u_{N}
\end{aligned}
$$

The back EMFs waveforms, the phase winding currents waveforms and the produced torque waveforms of the BLDC motor were shown in Fig.2. The areas where the commutation process made are indicated by dashed lines. In Fig.2, although the currents of the phase windings and the produced torque are constant, these outputs are not exactly constant due to the inductance of the stator windings [13]. Usually three-phase BLDC motor has two operating regions. These regions are referred to as conduction region and commutation region. In the conduction region, the two phase determined by the rotor position is conducting and the other phase is in isolation. In the commutation region, the current of one phase remains constant and the current transfer was realized between other two phases. In addition, each of the three phases (incoming phase, outgoing phase and non-commutation phase) are conducting at the commutation region [14]. It can be assumed that BLDC motor works like a normal DC motor at the conduction region and as a three phase $\mathrm{AC}$ motor at the commutation region. In view of this situation, torque ripples can be eliminated in commutation regions by coordinate transformation theory used in AC motor control [15]. If these two regions are compared on time basis, the duration of the commutation region is considerably shorter than the duration of the conduction region. The above described studies can be performed for inverters with both 120 and 180-degree conduction mode. In this study, we have used a 120-degree conduction mode. In the 120-degree conduction mode, during one electrically period, the upper group and lower group switches of the inverter are conduction each 120-degree. 


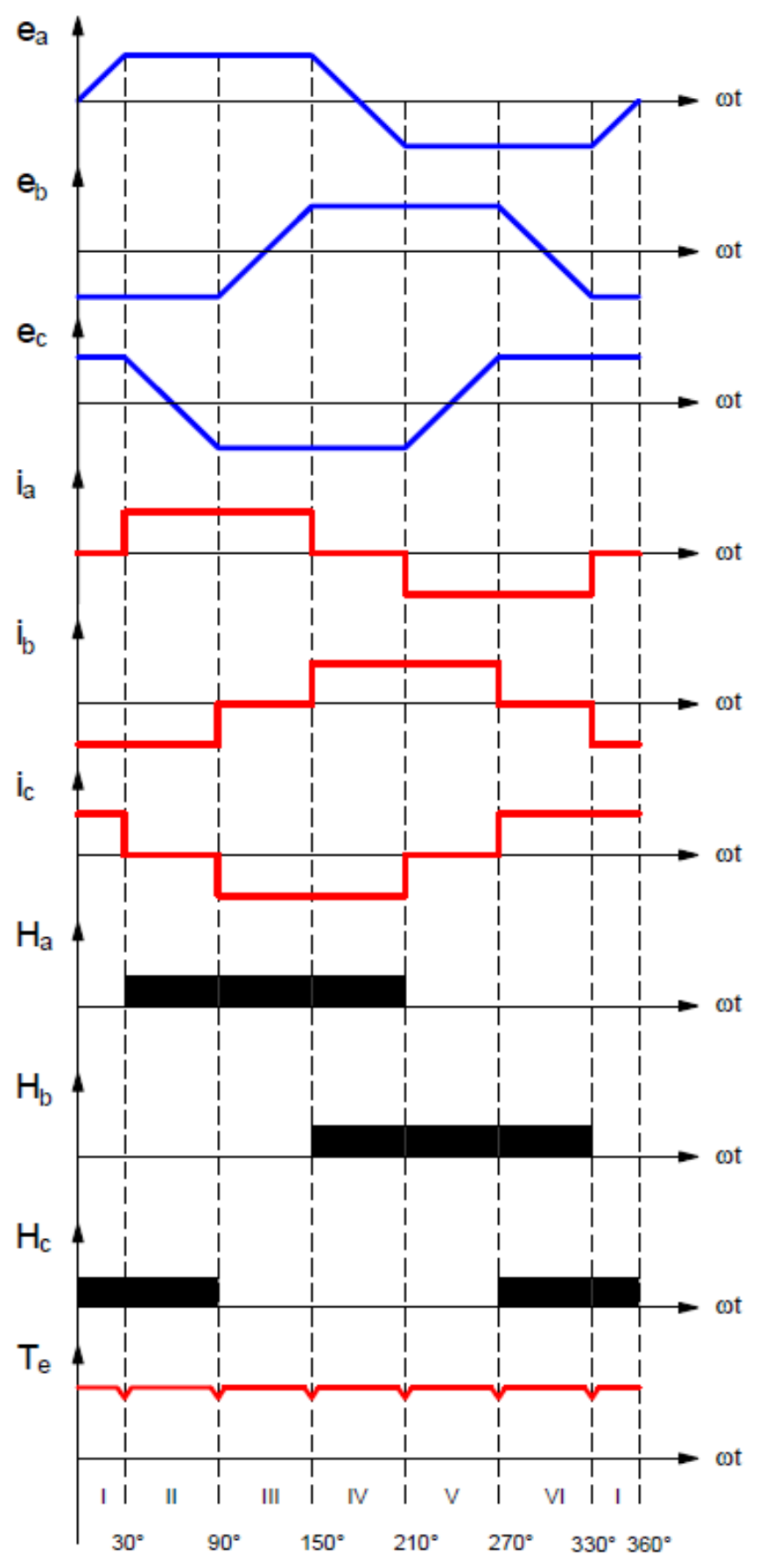

Fig. 2 The back EMFs, the phase winding currents, Hall sensor signal and the produced torque waveforms of the BLDCM

Assuming $R_{a}=R_{b}=R_{c}=R \quad$ and $\quad L_{a}=L_{b}=L_{c}=L$ then the mathematical model of BLDC motor from Eq. (1) can be obtained as follows;

$$
\left[\begin{array}{l}
u_{a} \\
u_{b} \\
u_{c}
\end{array}\right]=\left[\begin{array}{ccc}
R & 0 & 0 \\
0 & R & 0 \\
0 & 0 & R
\end{array}\right]\left[\begin{array}{l}
i_{a} \\
i_{b} \\
i_{c}
\end{array}\right]+\left[\begin{array}{ccc}
L & 0 & 0 \\
0 & L & 0 \\
0 & 0 & L
\end{array}\right] \frac{d}{d t}\left[\begin{array}{c}
i_{a} \\
i_{b} \\
i_{c}
\end{array}\right]+\left[\begin{array}{c}
e_{a} \\
e_{b} \\
e_{c}
\end{array}\right]+\left[\begin{array}{l}
u_{N} \\
u_{N} \\
u_{N}
\end{array}\right]
$$

Where, $u_{a}, u_{b}, u_{c}$ terminal phase voltages $i_{a}, i_{b}, i_{c}$ phase currents, $e_{a}, e_{b}, e_{c}$ phase back EMFs, $R$ phase resistance, $L=$
$L_{s}$ - $M$ phase inductance, $L_{s}$, phase self-inductance and $M$ mutual inductance and $u_{N}$, the neutral point voltage of the starconnected motor, respectively.

The electrical power produced by each phase;

$$
\begin{aligned}
& P_{a}=e_{a} i_{a} \\
& P_{b}=e_{b} i_{b} \\
& P_{c}=e_{c} i_{c}
\end{aligned}
$$

Expression of total electromagnetic torque produced by BLDC motor is;

$$
\begin{gathered}
T_{e}=\frac{P_{\text {sum }}}{\omega_{m}}=\frac{P_{a}+P_{b}+P_{c}}{\omega_{m}} \\
T_{e}=\frac{e_{a} i_{a}+e_{b} i_{b}+e_{c} i_{c}}{\omega_{m}}
\end{gathered}
$$

Where, represents, $P_{a}, P_{b}, P_{c}$ the electrical powers produced by the phases, $P_{\text {sum }}$ the sum of these powers, $T_{e}$, the electromagnetic torque and $\omega_{m}$ the mechanical speed of the rotor, respectively.

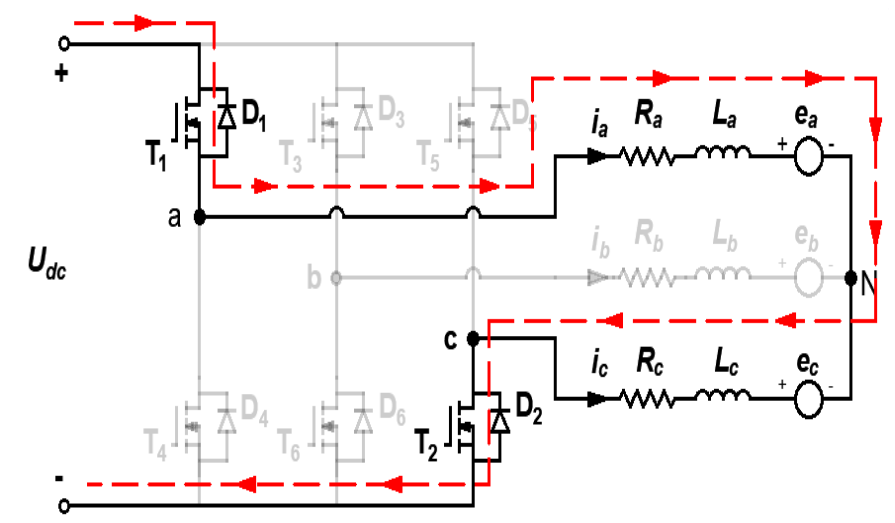

Fig. 3 The conduction region before commutation $\left(\mathrm{a}^{+} \mathrm{c}^{\mathrm{c}}\right)$

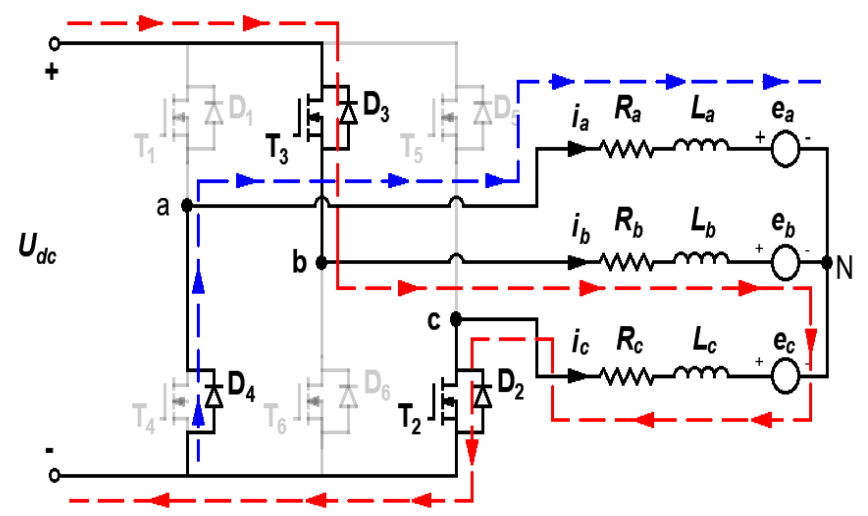

Fig. 4 The commutation region (Three phase are conducting)

All phase currents during the commutation will not be a square wave as shown in Fig.2 due to the inductance of the stator phase windings. In order to perform this analysis, it was assumed that the commutation process passes from phase $a$ to 
phase $b$, as seen from Figs.3, 4, 5. In this case, the phase $a$ is named outgoing phase and phase $b$ is named incoming phase.

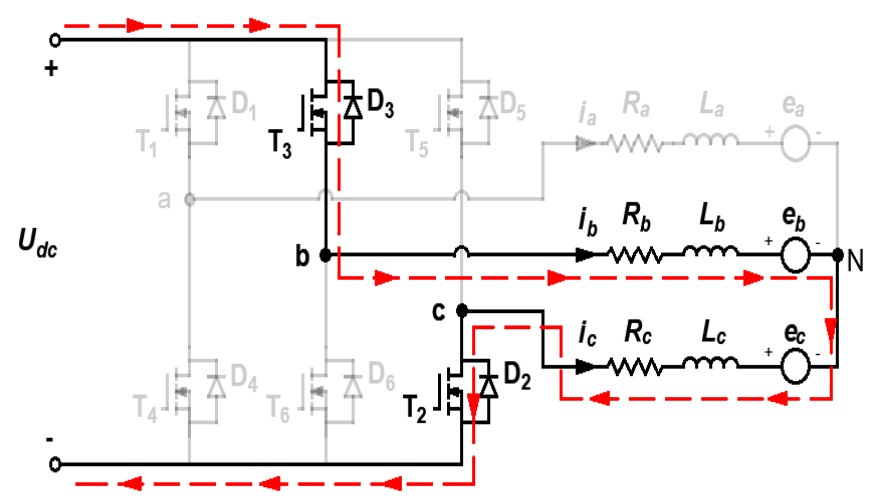

Fig. 5 The conduction region after commutation $\left(\mathrm{b}^{+} \mathrm{c}^{-}\right)$

As seen from the Fig.3, the currents of the phase windings can be expressed as $i_{a}=-i_{c}=I_{m}$ and $i_{b}=0$ in the conduction period and as seen from the Fig. $4, i_{a}=0$ and $i_{b}=-i_{c}=I_{m}$ in the commutation period. $I_{m}$, is represent the maximum value of phase currents. The conduction region after commutation and the conduction region before commutation are same. There is only phase change (from $a c$, to $b c$ ) like Figs. 3 and 5. The commutation phase sequence is $a b-a c-b c-b a-c a-$ $c b$. This case is shown in Fig.6.

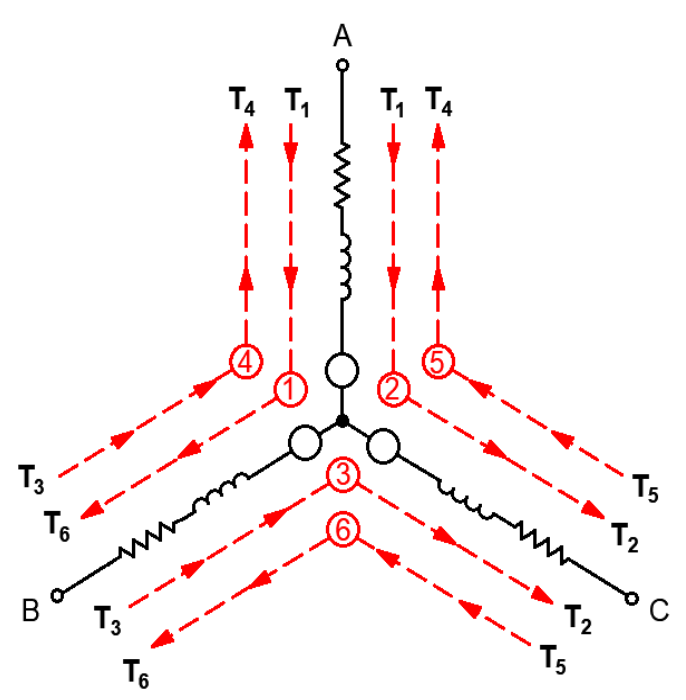

Fig. 6 The commutation phase sequence

Since the the commutation time is very short, within this period the back EMFs induced in the phases can be considered constant. $e_{a}=e_{b}=E_{m}$ and $e_{c}=-E_{m}$. If these magnitudes are substituted in Eq. (5);

$$
\begin{aligned}
& T_{e}=\frac{e_{a} i_{a}+e_{b} i_{b}+e_{c} i_{c}}{\omega_{m}}=\frac{2 E_{m} I_{m}}{\omega_{m}}=-\frac{2 E_{m} i_{c}}{\omega_{m}} \\
& \omega_{m}=-\frac{2 E_{m} i_{c}}{T_{e}}
\end{aligned}
$$

As seen from the second statement of Eq. (6), the fluctuations in the current of the non-commutation phase directly affect the rotor speed. By reducing the fluctuations in this current, the speed fluctuations can be eliminated. At the commutation time, the current of phase $a$, will flow through the freewheeling diode D4, as similar Fig.4. In addition to this, the voltage on the free-wheeling diodes was neglected. If the expression of the three-phase terminal voltages substituted in Eq. (1) $u_{a}=u_{c}=0$ and $u_{b}=U_{d c}$,

$$
\begin{aligned}
& 0=R i_{a}+L \frac{d i_{a}}{d t}+e_{a}+u_{N} \\
& U_{d c}=R i_{b}+L \frac{d i_{b}}{d t}+e_{b}+u_{N} \\
& 0=R i_{c}+L \frac{d i_{c}}{d t}+e_{c}+u_{N}
\end{aligned}
$$

The neutral point voltage of the star-connected phase windings of BLDC motor at the commutation times is different from zero [16]. If Eq. (7) is collected one under the other, the expression of neutral point voltage of BLDC motor is:

$$
\begin{aligned}
& 3 u_{N}=U_{d c}-E_{m} \\
& u_{N}=\frac{U_{d c}-E_{m}}{3}
\end{aligned}
$$

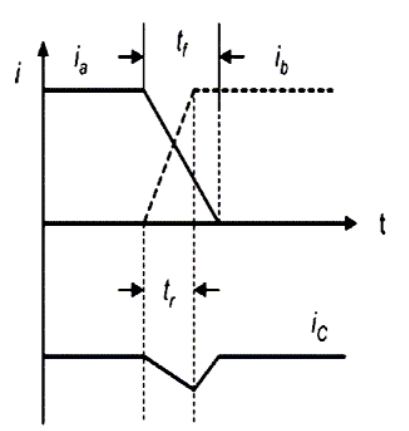

a

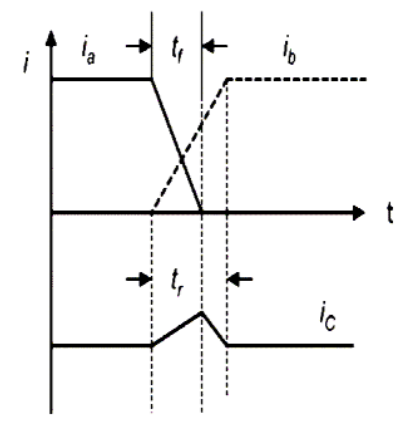

b

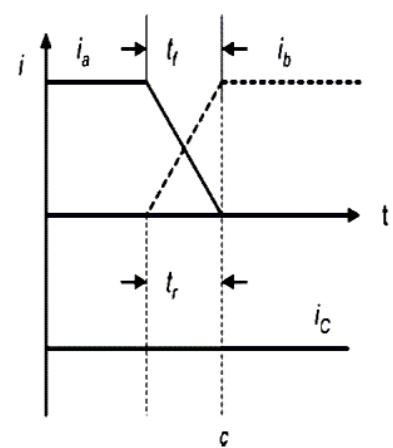

Fig. 7 The phase current behavior of commutation region, a.) $t_{f}>t_{r}$, b.) $t_{f}<t_{r}$, c.) $t_{f}=t_{r},[4]$.

The slopes of the incoming and outgoing phase currents in the conventional BLDC motor speed control system are different each other at both high and low speeds. This difference is caused by the torque and speed fluctuations in commutation intervals. In order to eliminate the fluctuations in the rotor 
speed, it is necessary to equalize the slopes of the incoming and outgoing phase currents at the commutation time or keep constant the current of the non-commutation phase. The current behavior of BLDC motor was shown in Fig.7. Where, $t_{f}$, represents the fall time of outgoing phase from the maximum to zero, $t_{r}$, represents the rise time of incoming phase from the zero to the maximum value. As seen in Fig. $7 \mathrm{a}$ and $7 b$, the rise time is different from the fall time. In this case, are occurs fluctuations in the non-commutation phase. According to the Eq. (6), the amplitude of the noncommutation phase current is directly related to the generated torque. In this case, creates fluctuations in both the output torque and the output speed. However, in Fig.7c, it is seen that there is no fluctuation in the non-commutation phase when the slopes of the incoming and outgoing phase currents are equalized. When the Eqs. (7) and (8) are evaluated together, the slopes of the currents of incoming, outgoing and noncommutation phase at the commutation time can be expressed as follows;

$$
\begin{aligned}
& \frac{d i_{a}}{d t}=-\frac{\left(U_{d c}+2 E_{m}\right)}{3 L} \\
& \frac{d i_{b}}{d t}=\frac{2\left(U_{d c}-E_{m}\right)}{3 L} \\
& \frac{d i_{a}}{d t}+\frac{d i_{b}}{d t}=-\frac{d i_{c}}{d t} \\
& \frac{d i_{c}}{d t}=-\frac{\left(U_{d c}-4 E_{m}\right)}{3 L}
\end{aligned}
$$

Where, $U_{d c}$ represents DC link voltage and $E_{m}$, represents maximum value of the back EMF, respectively. In Eq. (10), the resistance of the phase windings $R$ was neglected. This is because the commutation interval is much shorter than the electrical time constant $L / R$ [3]. In this case, the fall time of phase $a$ from the maximum value to zero and the rise time of phase $b$ from the zero to maximum value, can be calculated as follows.

$$
\begin{aligned}
& t_{f}=\frac{3 L I_{m}}{U_{d c}+2 E_{m}} \\
& t_{r}=\frac{3 L I_{m}}{2\left(U_{d c}-E_{m}\right)}
\end{aligned}
$$

According to the Fig.7c, the fluctuations in produced torque, rotor speed and the non-commutation phase can be eliminated if the slopes of the incoming and outgoing phase currents are equal. If the fall and rise times in Eq. (10) are equalized;

$$
\begin{aligned}
t_{f} & =t_{r} \\
\frac{3 L I_{m}}{U_{d c}+2 E_{m}} & =\frac{3 L I_{m}}{2\left(U_{d c}-E_{m}\right)} \\
U_{d c} & =4 E_{m}
\end{aligned}
$$

As seen from Eq. (11), at the commutation intervals, the inverter input voltage $U_{d c}$ must be equal to four times of the back EMFs. So that the slopes of the incoming and outgoing phase currents are equal.

According to Eqs (6) and (9);

$$
\begin{aligned}
& T_{e}=-\frac{2 E_{m} i_{c}}{\omega_{m}} \\
& T_{c o m}=\frac{2 E_{m}}{\omega_{m}}\left(I_{m}+\frac{U_{d c}-4 E_{m}}{3 L} t\right)
\end{aligned}
$$

When the two expressions written for the torque in Eq (12) are considered together, the magnitude of the relative fluctuation in the commutation intervals can be expressed as in Eq (13).

$$
T_{r e l}=T_{c o m}-T_{e}=\frac{U_{d c}-4 E_{m}}{3 L} t
$$

Where, $T_{\text {com }}$ represents the value of the torque produced by BLDC motor, $T_{\text {rel }}$ represents relative torque ripple in the commutation intervals. The following inferences can be made according to Eq. (13).

a.) If $U_{d c}>4 E_{m}$, then $t_{f}>t_{r}$, and torque will continue to increase during commutation. The behavior of phase currents is similar to Fig.7a.

b.) If $U_{d c}<4 E_{m}$, then $t_{f}<t_{r}$, and torque will continue to decrease during commutation. The behavior of phase currents is similar to Fig. $7 \mathrm{~b}$.

c.) If $U_{d c}=4 E_{m}$, then $t_{f}=t_{r}$, and torque remains constant during commutation. The behavior of phase currents is similar to Fig.7c.

According to the Eqs. (11) and (13), it is theoretically seen that if the input voltage of the inverter is equal to four times of the back EMF at the commutation intervals, torque ripples can be completely zero. This equalization was carried out using different DC-DC converters [6, 17-19]. In most of the studies, it was assumed that the rotor speed was constant in the commutation intervals. But in fact, the fluctuations occur at the rotor speed, as well as the produced torque. In this study, it was proposed to reduce the speed fluctuations by using DC link current. Commutation signals were produced for specific points of the current commutation and it was applied to designed voltage selective circuit. This study has been proposed for the suppression of speed fluctuations by synchronizing the inverter input voltage to four times of the produced back EMF, with a new switching technique at the commutation intervals.

\section{PROPOSED CONTROL STRATEGY}

The designed voltage selective circuit for the proposed method is shown in Fig.8. In this method, two different regulated voltage sources were used to reduce the speed fluctuations. These sources, generate voltage according to the signal from given their inputs. The source number 1, will be conducting during commutation periods and will remain in isolation during non-commutation periods. A second feedback link was designed by taking four times the maximum value of the 
produced back EMF by using a second adjustable voltage source. The source number 2 , will only be conducting during non-commutation periods and will be kept in isolation during commutation periods.

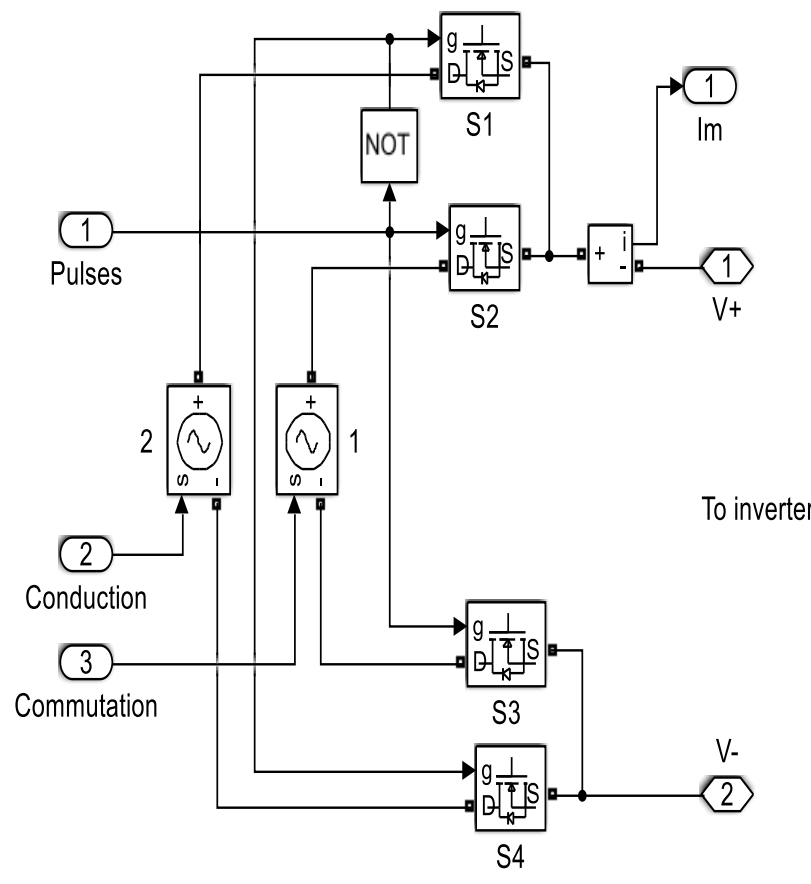

Fig. 8 Designed voltage selective circuit

In the proposed technique, there is no need to calculate the commutation time. A new switching technique has been proposed from the relation between the torque magnitude of the motor, the speed of the motor and the maximum value of the phase current. The expression of this relation;

$$
\begin{aligned}
& T_{e}=k_{t} I \\
& I=\frac{T_{e}}{k_{t}}
\end{aligned}
$$

Where, $k_{t}$ represents the motor torque constant, $I$ the maximum value of the source current.

The following inferences can be made using the second expression of Eq. (14).

a.) If $I<T_{e} / k_{t}$, then commutation process was started. In this case the inverter input voltage set to $U_{d c}=4 E_{m}$.

b.) If $I>=T_{e} / k_{t}$, then the commutation was finished. In this case the inverter input voltage set to $U_{d c}$.

According to these inferences, a commutation time switching signal was generated for the moments where the maximum current falls below the $T_{e} / k_{t}$ ratio and this signal was applied to the designed voltage selective circuit during the commutation period. The signal obtained by the proposed technique is shown in Fig.9. Inverter gate signals generated by hall effect sensors with respect to the rotor position is shown in Fig9a. These signals are applied to the power MOSTETs in the inverter. The inverter changes state according to these signals. In Fig.9b, the sawtooth graph represents the maximum value of the source current (magenta), while the constant graph represents the $T_{e} / k_{t}$ ratio (dashed black). Fig.9c shows the generated commutation signals when the source current falls below $T_{e} / k_{t}$ ratio. These signals were applied to the voltage selective circuit at commutation time. In order to reduce the speed fluctuations occurring commutation intervals, it was tried to provided $U_{d c}=4 E_{m}$.

a.)

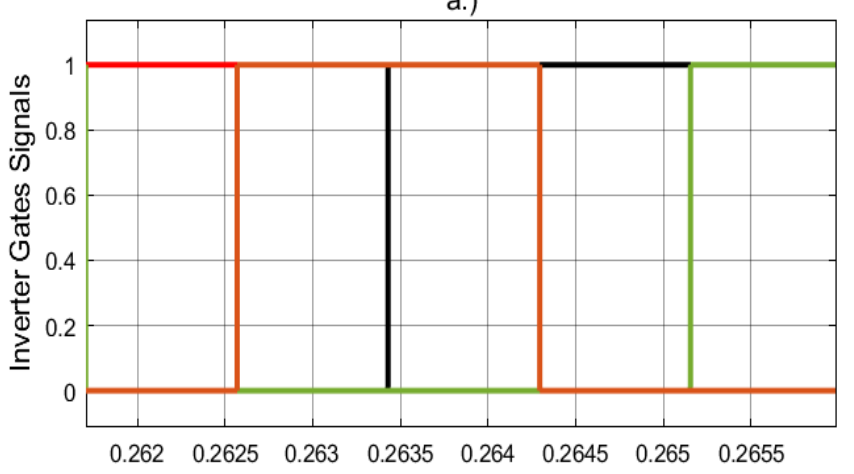

b.)

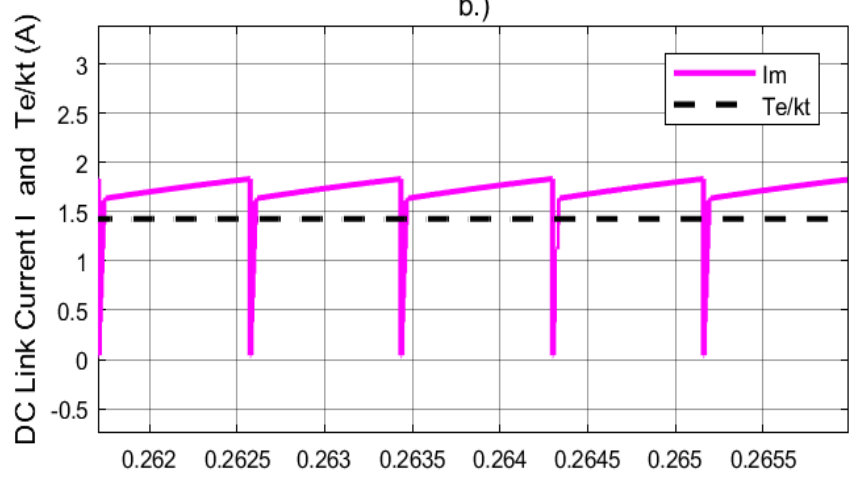

c.)

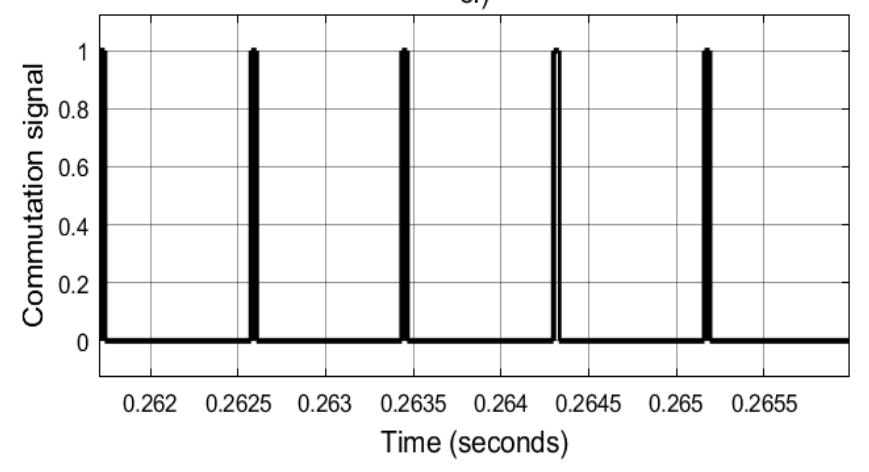

Fig. 9a.) Inverter gate signal, b.) Dc link current and $T_{e} / k_{t}$ ratio c.) The produced commutation signal.

When the BLDC motor was started, the value of the maximum source current was measured and compared with the $T_{e} / k_{t}$ ratio. If $T_{e} / k_{t}$ ratio is smaller than the value of the source current, then the designed voltage selective circuit is providing $U_{d c}=4 E_{m}\left(S_{1}\right.$ and $S_{4}$ switch on $)$. If the source current is greater than or equal to $T_{e} / k_{t}$, the inverter input voltage is not changed and remain $U_{d c}\left(S_{2}\right.$ and $S_{3}$ switch on). The simulink models of the two control method for BLDC motor is shown in Fig.10. 


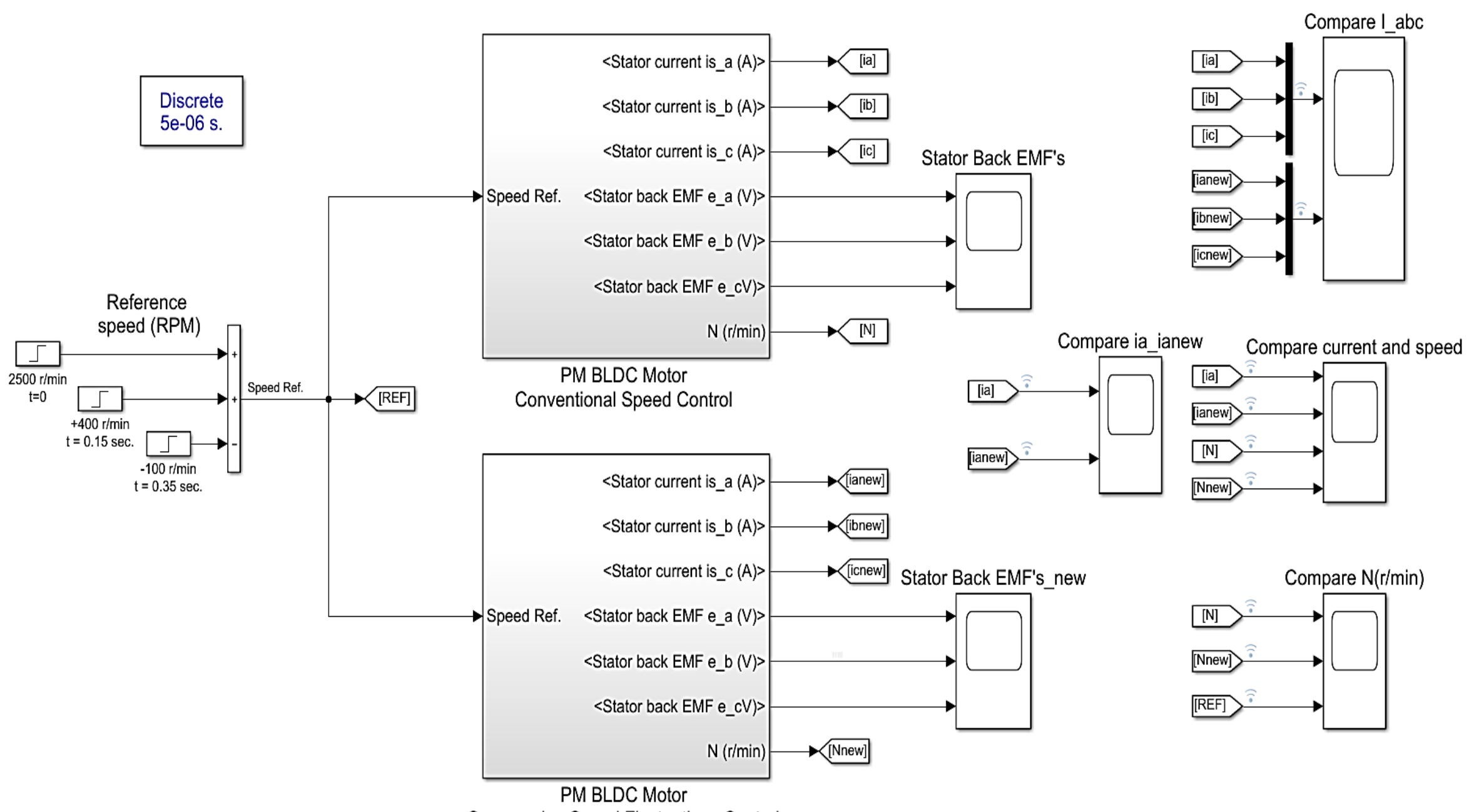

Suppressing Speed Fluctuations Control

Fig. 10 Convantional and Proposed control method Simulink Models. 
Parameters of the BLDC motor used in the simulation were given in Table I, and the flowchart of the proposed control method is shown in Fig. 11.

TABLE I

BLDC MOTOR PARAMETERS USED IN SIMULATON.
\begin{tabular}{|l|l|l|}
\hline \multicolumn{1}{|c|}{ Parameters } & \multicolumn{1}{c|}{ Unit } & \multicolumn{1}{c|}{ Value } \\
\hline Phase Resistance & $\Omega$ & 2.875 \\
\hline Phase Inductance & $\mathrm{mH}$ & 8.5 \\
\hline Back EMF Coefficient & $\mathrm{V} /(\mathrm{rad} / \mathrm{s}$ & 0.7 \\
\hline Pole Pairs & & 4 \\
\hline Rated Voltage & $\mathrm{V}$ & 500 \\
\hline Rated Speed & $\mathrm{r} / \mathrm{min}$ & 3000 \\
\hline Rated Torque & $\mathrm{N} . \mathrm{m})$. & 2 \\
\hline Rated Power & $\mathrm{W}$ & 1000 \\
\hline
\end{tabular}

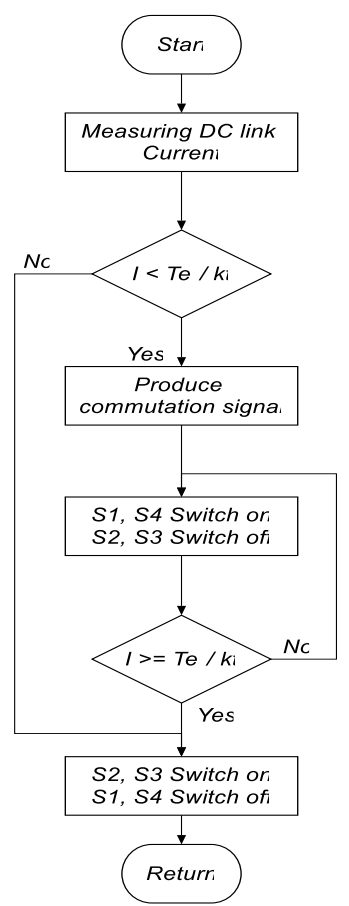

Fig. 11 The flowchart of the proposed control method

\section{SIMULATION RESULTS}

As seen from the Fig.10, a reference speed of $2500 \mathrm{r} / \mathrm{min}$ was applied to BLDC motor at startup. Then, this speed was increased by $2900 \mathrm{r} / \mathrm{min}$ at $t=0.15 \mathrm{~s}$ and reduced by 2800 $\mathrm{r} / \mathrm{min}$ at $t=0.35 \mathrm{~s}$. The currents of the phase windings for the two control methods, the current of the phase $a$, the rotor speeds are shown in Figs.12, 13, 14, respectively. Fig.12a shows the fluctuations of the phase currents in the conventional control method. These fluctuations negatively affect the output speed and cause power loss. In Fig. 12b, these fluctuations were tried to be suppressed by the proposed control method. Fig.13 shows the time-dependent current of phase $a$, both the conventional control method and the proposed control method. Fig. 14 shows comparison of rotor speeds. In both control methods, rotor speeds followed the given reference speed in all speed ranges. But in conventional control method, the rotor speed fluctuation is considerably higher with respect to proposed control method. This case, is shown in Figs.15, 16, 17, respectively. According to the simulation results it was observed that the disturbances occurring in the phase currents affect the rotor speed directly. This effect is similar to the non-commutation phase current.
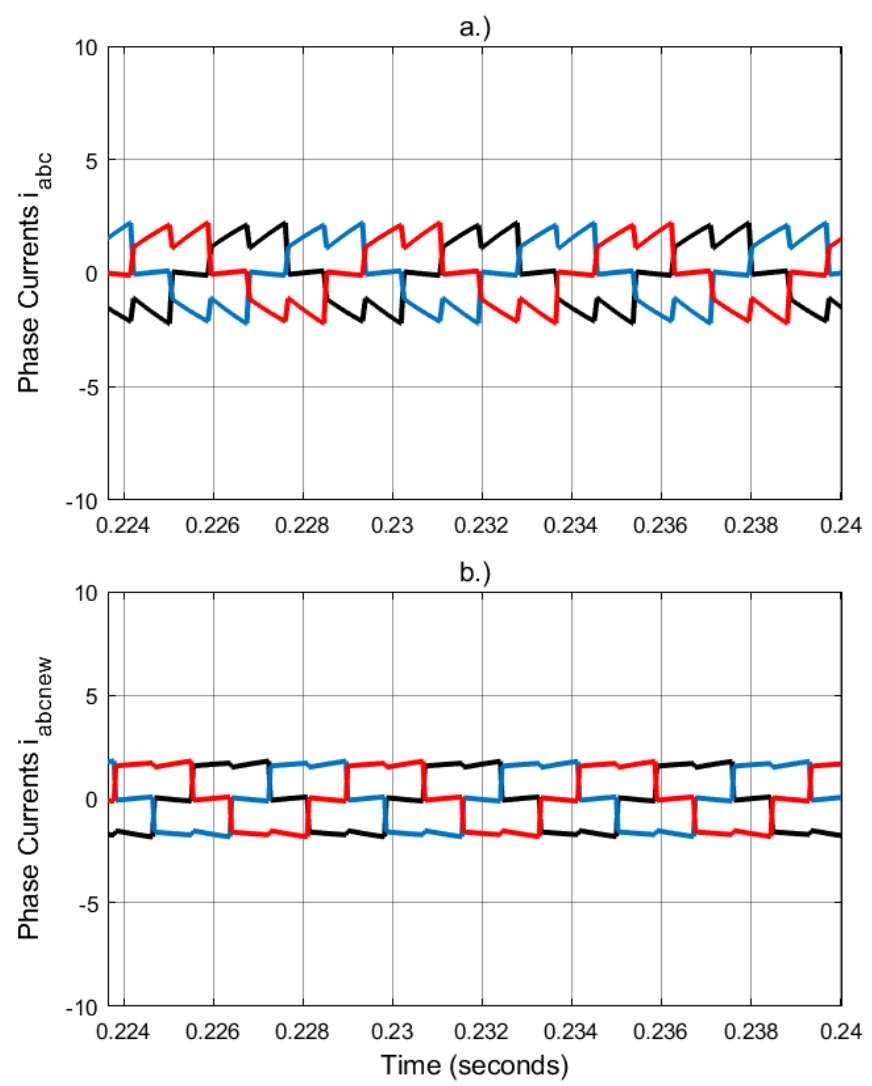

Fig. 12 The phase currents a.) Conventional control b.) Proposed Control
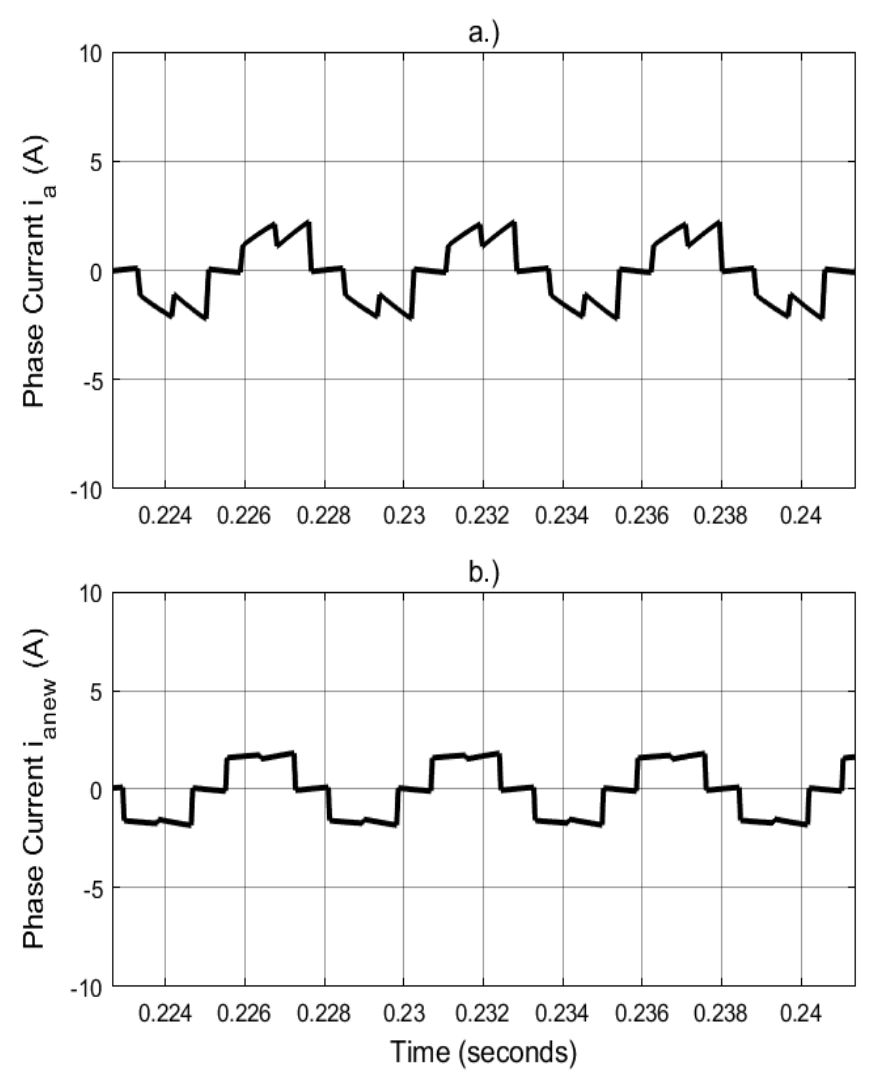

Fig. 13 The current of phase a, a.) Conventional control b.) Proposed Control 
BALKAN JOURNAL OF ELECTRICAL \& COMPUTER ENGINEERING, Vol. 7, No. 3, July 2019

This effect can be calculated as a percentage in Eq. (15).

$$
\omega_{\text {fluct }}=\frac{\omega_{\max }-\omega_{\min }}{\omega_{\max }+\omega_{\min }} * 100 \%
$$

The numerical results obtained from the simulation are given in Table II. As shown in Table II, the fluctuations in the rotor speed of the BLDC motor were greatly reduced with the proposed control method.

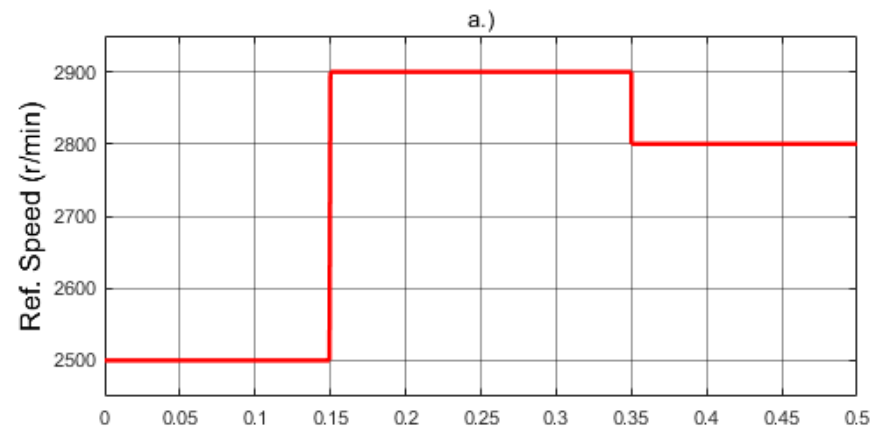

b.)

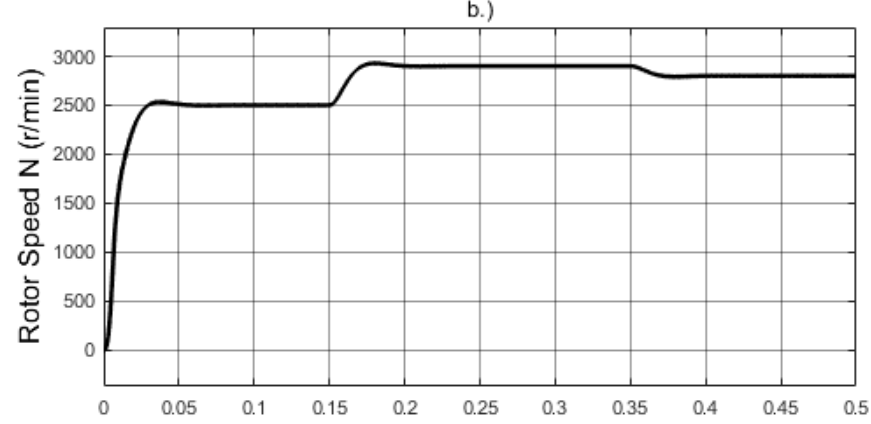

c.)

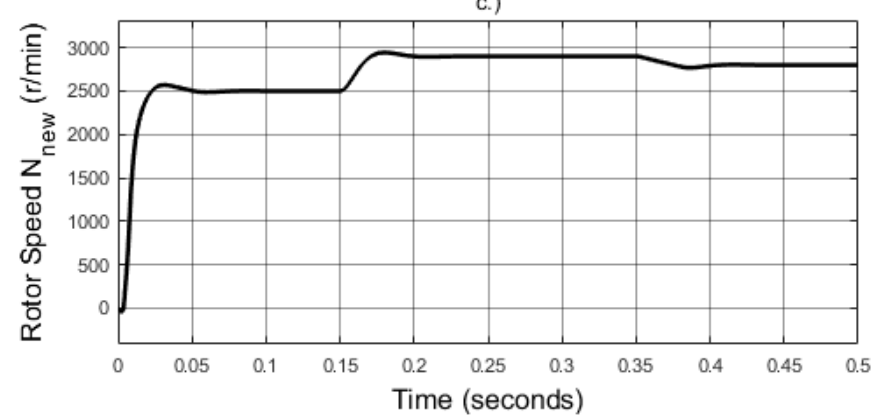

Fig. 14. The rotor speed a.) Reference b.) Conventional control c.) Proposed control
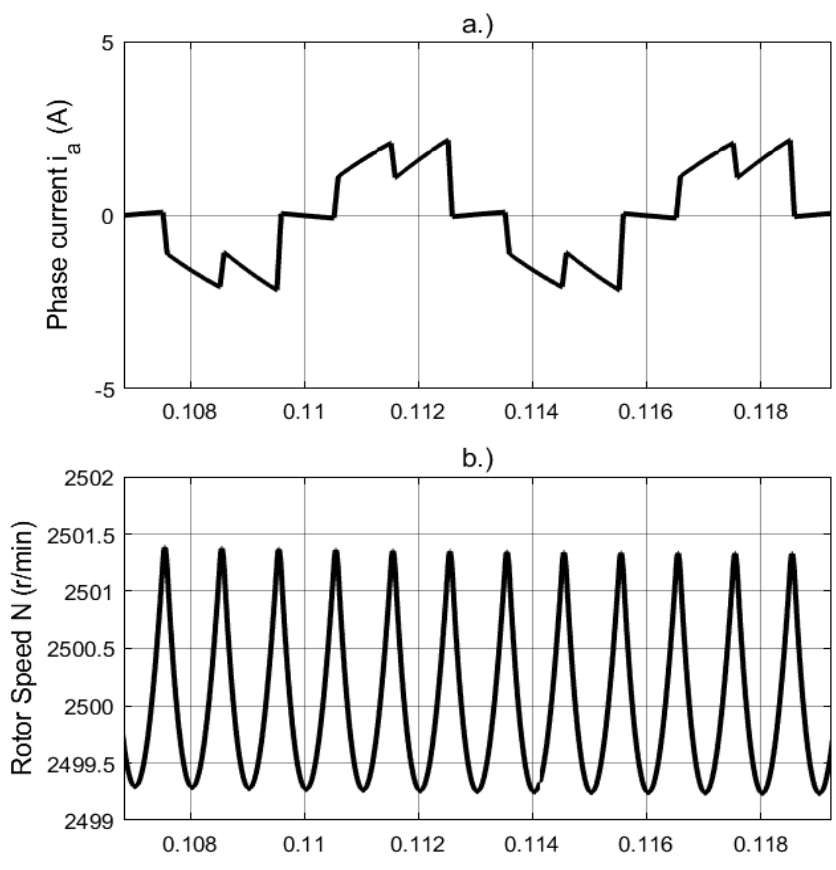

c.)

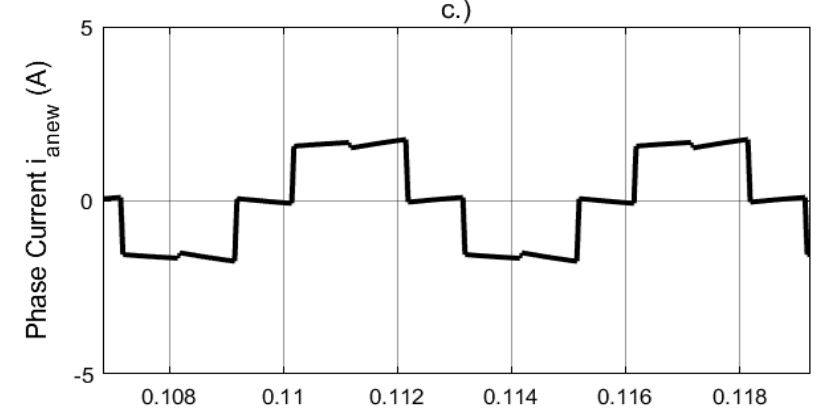

d.)

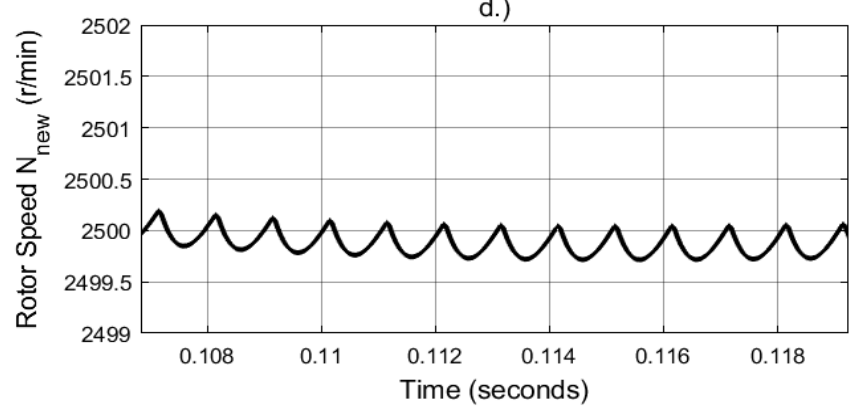

Fig. 15. Simulation results a.) Phase current and b.) Rotor speed, of conventional control, c.) Phase current and d.) Rotor speed, of proposed control, respectively. $\left(\omega_{\text {ref }}=2500 \mathrm{r} / \mathrm{min}\right.$, from $t=0$ to $\left.t=0.15 \mathrm{~seconds}\right)$

TABLE II

SPEED FLUCTUATIONS FOR GIVEN REFERENCE

\begin{tabular}{|l|c|c|c|}
\hline Ref. Speed (r/min) & \multicolumn{2}{|c|}{2500 (from $t=0$ to $t=0.15$ seconds) } \\
\hline Speed intervals and fluctuation & Max (r/min) & Min (r/min) & Fluctuation (r/ms) \\
\hline Conventional control & 2501.3 & 2499.3 & 2 \\
\hline Proposed control & 2500.24 & 2499.9 & 0.34 \\
\hline Ref. Speed (r/min) & \multicolumn{2}{|c|}{2900 (from $t=0.15$ to $t=0.35$ seconds $)$} \\
\hline Speed intervals and fluctuation & Max (r/min) & Min (r/min) & Fluctuation (r/ms) \\
\hline Conventional control & 2901.3 & 2898.97 & 2.326 \\
\hline Proposed control & 2900.12 & 2899.725 & 0.395 \\
\hline Ref. Speed (r/min) & \multicolumn{2}{|c|}{2800 (from $t=0.35$ to $t=0.5$ seconds) } \\
\hline Speed intervals and fluctuation & Max (r/min) & Min $(\mathrm{r} / \mathrm{min})$ & Fluctuation (r/ms) \\
\hline Conventional control & 2801.3 & 2799.066 & 2.234 \\
\hline Proposed control & 2800.24 & 2799.9 & 0.379 \\
\hline
\end{tabular}



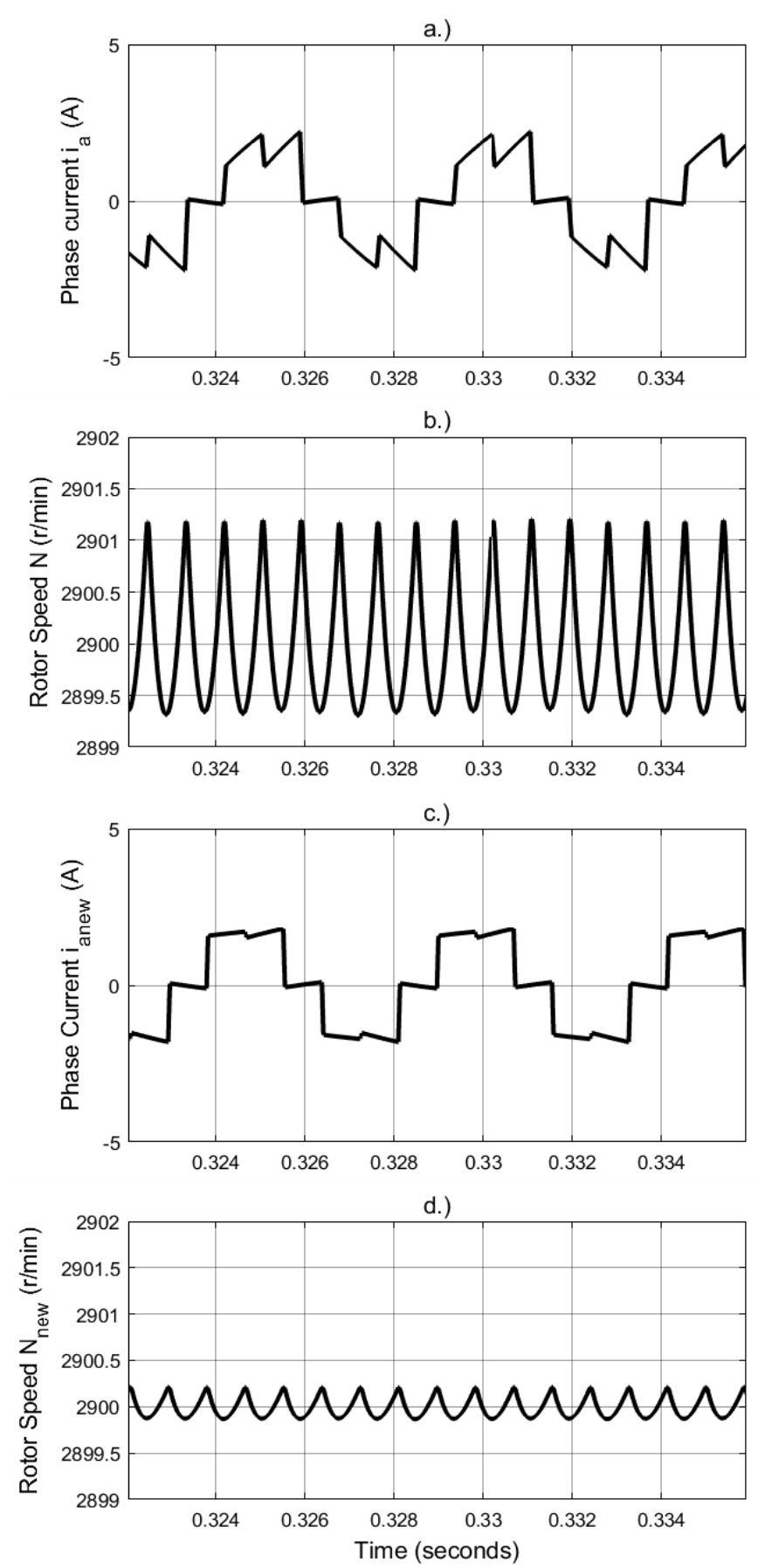

Fig. 16 Simulation results a.) Phase current and b.) Rotor speed, of conventional control, c.) Phase current and d.) Rotor speed, of proposed control, respectively, $\left(\omega_{\text {ref }}=2900 \mathrm{r} / \mathrm{min}\right.$, from $t=0.15$ to $t=0.35$ seconds $)$.

\section{CONCLUSIONS}

In this study, a new control method has been proposed to reduce the speed fluctuations in the BLDC motors. In this method, it was aimed to equalize the slopes of the incoming and outgoing phase currents. Both theoretical calculations and simulation results, the fluctuation in the current, which is noncommutation phase, has been shown to directly affect the rotor speed. There is only a single voltage selective circuit was used to minimization these fluctuations. This circuit was only used in commutation regions. In non-commutation regions, the conventional BLDC motor control circuit was used. The mainly advantage of the proposed method are that it does not require heavy theoretical calculations such as calculating commutation times.
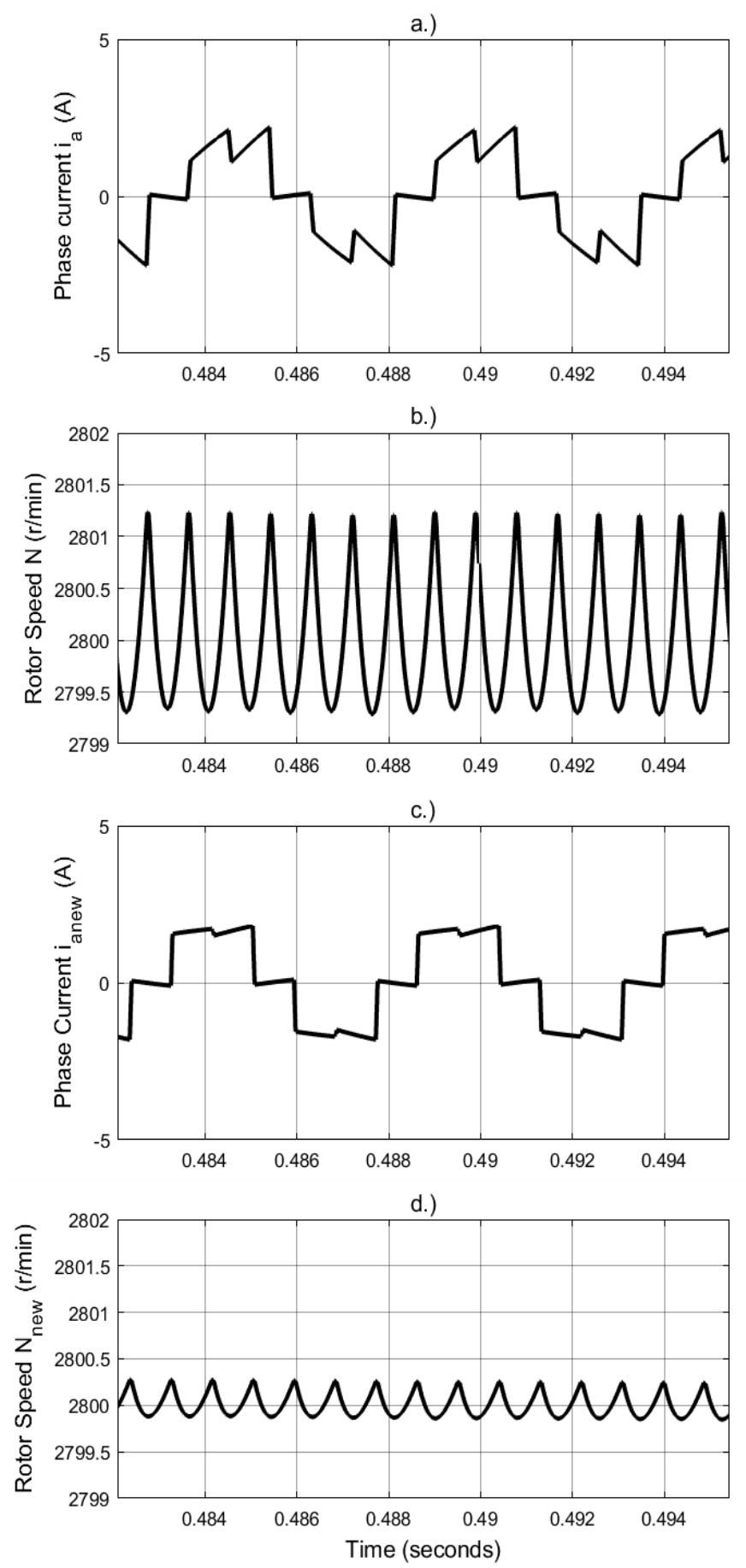

Fig. 17 Simulation results a.) Phase current and b.) Rotor speed, of conventional control, c.) Phase current and d.) Rotor speed, of proposed control, respectively, $\left(\omega_{\mathrm{ref}}=2500 \mathrm{r} / \mathrm{min}\right.$, from $t=0.35$ to $\left.t=0.5 \mathrm{~seconds}\right)$.

According to the simulation results, it was observed that the speed fluctuations are greatly reduced for all speed ranges in steady state condition. Reducing these fluctuations is highly effective both the longer life and the more efficient operation of the BLDC motor. 


\section{REFERENCES}

[1] Shi, J. and Li, T. C., New Method to Eliminate Commutation Torque Ripple of Brushless DC Motor with Minimum Commutation Time, IEEE Transactions on Industrial Electronics, 60, 6 (2013) 2139-2146.

[2] Xiaofeng, Z. and Zhengyu, L., A New BLDC Motor Drives Method Based on BUCK Converter for Torque Ripple Reduction, 5th International Power Electronics and Motion Control Conference (CES/IEEE), August 2006, Shanghai, China, 1-4.

[3] Shi, T., Guo, Y., Song, P.and Xia, C., A New Approach of Minimizing Commutation Torque Ripple for Brushless DC Motor Based on DC-DC Converter, IEEE Transactions on Industrial Electronics, 57, 10 (2010) 3483-3490.

[4] Viswanathan, V. and Seenithangom, J., Approach for Torque Ripple Reduction for Brushless DC Motor Based on Three-level Neutral-pointclamped Inverter with DC-DC Converter, IET Power Electronics, 8, 1 (2015) 47-55.

[5] Carlson, R., Lajoie-Mazenc, M. and Fagundes, J. C. d. S., Analysis of Torque Ripple Due to Phase Commutation in Brushless DC Machines, IEEE Transactions on Industry Applications, 28, 3 (1992) 632-638.

[6] Chen, W., Liu, Y., Li, X., Shi, T. and Xia, C., A Novel Method of Reduction Commutation Torque Ripple for Brushless DC Motor Based on Cuk Converter, IEEE Transactions on Power Electronics, 32, 7 (2017) 5497-5507.

[7] Song, J. H. and Choy, I., Commutation Torque Ripple Reduction in Brushless DC Motor Drives using a Single DC Current Sensor, IEEE Transactions on Power Electronics, 19, 2 (2004) 312-319.

[8] Cao, Y., Shi, T., Liu, Y. and Wang, Z. Commutation Torque Ripple Reduction for Brushless DC Motors with Commutation Time Shortened, IEEE International Electric Machines and Drives Conference (IEMDC), May 2017, Miami, FL, USA, 1-7.

[9] Fang, J., Li, H. and Han, B., Torque Ripple Reduction in BLDC Torque Motor with Nonideal Back EMF, IEEE Transactions on Power Electronics, 27, 11 (2012) 4630-4637.

[10] Li, X., Xia, C., Cao, Y., Chen, W. and Shi, T., Commutation Torque Ripple Reduction Strategy of Z-Source Inverter Fed Brushless DC Motor, IEEE Transactions on Power Electronics, 31, 11 (2016) 76777690.

[11] Shi, T., Niu, X., Chen, W. and Xia, C., Commutation Torque Ripple Reduction of Brushless DC Motor in Braking Operation, IEEE Transactions on Power Electronics, 33, 2 (2018) 1463-1475.

[12] Lad, C. K. and Chudamani, R., A Simple Overlap Angle Control Strategy for Reducing Commutation Torque Ripple in a Brushless DC Motor Drive, Engineering Science and Technology, an International Journal, 20 (2017) 1406-1419.

[13] Niasar, A. H., Vahedi, A. and Moghbelli, H., A Novel Method for Commutation Torque Ripple Reduction of Four-Switch, Three-Phase Brushless DC Motor Drive, Iranian Journal of Electrical \& Electronic Engineering, 3, 3 (2007) 83-96.

[14] Chuang, H. S., Ke, Y. L. and Chuang, Y. C., Analysis of Commutation Torque Ripple using Different PWM Modes in BLDC Motors, IEEE Industrial \& Commercial Power Systems Technical Conference, May 2009, Calgary, Canada, 1-6.

[15] Jiang, W., Huang, H., Wang, J., Gao, Y. and Wang, L., Commutation Analysis of Brushless DC Motor and Reducing Commutation Torque Ripple in the Two-Phase Stationary Frame, IEEE Transactions on Power Electronics, 32, 6 (2017) 4675-4682.

[16] Brendsen, C. S., Champenois, G. and Bolopion, A., Commutation Strategies for Brushless DC Motors: Influence on Instant Torque, IEEE Transactions on Power Electronics, 8, 2 (1993) 231-236.

[17] Amirthalingam, R. and Mahadevan, B., A New Approach for Minimizing Torque Ripple in a BLDC Motor Drive with a Front end IDO DC-DC Converter, Turkish Journal of Electrical Engineering \& Computer Science, 25 (2017) 2910-2921.

[18] Jogarao, R., Reddy, M. and Ashok, G., Analysis of Commutation Torque Ripple Minimization for Brushless DC Motor Based on SEPIC Converter, International Journal of Engineering Research and Application, 6, 11 (2016) 5-11.

[19] Chen, Z., Zhang, H., Liu, X., Hu, H., Zhao, J. and Gao, C., A New Method to Suppress the Commutation Torque Ripple for BLDC Motor Based on ZETA Converter, 6th International Conference on Power Electronics Systems and Applications (PESA), December 2015, Hong Kong, China, 1-6.

\section{BIOGRAPHIES}

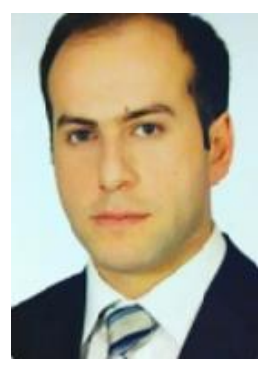

M. RESİT CYORAPSIZ was born in Erzurum, Turkey, in 1984. He received the first B.S. degree from Firat University, Elazig, Turkey, and the second B.S. degree from Ataturk University, Erzurum, Turkey, and the M.S. degree from Karadeniz Technical University, Trabzon, Turkey, in 2009, 2015, 2018, respectively, all in electrical engineering. Since 2018, he studies Ph.D. in electrical engineering at the Karadeniz Technical University. He has been a member of the Chamber of Electrical Engineers in Turkey.

Currently, he is an Instructor with the Department of Electrical and Energy, Vocational School of Technical Science, Bayburt University, Bayburt, Turkey. His research interests include power electronics and electric drive systems, control of electric machinery, electric vehicles, smart grid and power management in electric vehicles.

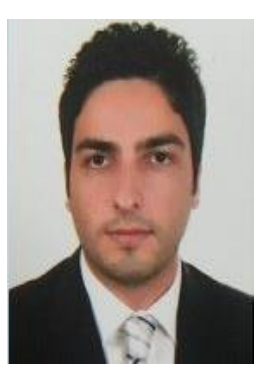

HAKAN KAHVECI was born in Kırşehir, Turkey. He received his B.Sc degree in Electrical Engineering and Ph.D degree from Karadeniz Technical University (KTU), Turkey, in 2006 and 2013, respectively.

He is currently an assistant professor in Electrical and Electronics Engineering Department at KTU. He has been a member of the Chamber of Electrical Engineers in Turkey. He works on electrical machine control systems and power electronics.

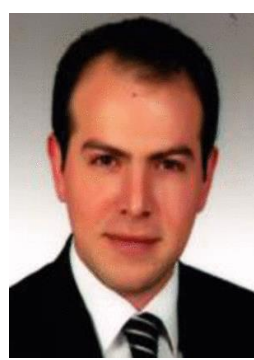

M. FATİH ÇORAPSIZ was born in Erzurum, Turkey, in 1981. He received the first B.S. degree from Firat University, Elazig, Turkey, in 2003, and the M.S. and Ph.D. degrees and the second B.S. degree from Ataturk University, Erzurum, Turkey, in 2009, 2014 and 2016, respectively, all in electrical engineering. He has been a member of the Chamber of Electrical Engineers in Turkey.

Currently, he is a Assistant Professor with the Department of Electrical and Electronics Engineering, College of Engineering, Ataturk University, Erzurum, Turkey. His research interests include theory of mechatronic and robotic systems, DC-DC converters, and motor drive circuits, with a focus on observation and estimation-based control. 